\title{
Estudo experimental da ligação de painéis de OSB com perfis do reticulado metálico do sistema construtivo Light Steel Framing
}

\author{
Joseph Stéphane Datchoua ${ }^{1 *}$, Francisco Carlos Rodrigues ${ }^{2}$ e Rodrigo Barreto \\ Caldas $^{3}$ \\ ${ }^{1}$ Escola de Engenharia, Universidade Federal de Minas Gerais, \\ josephstephane21@yahoo.fr \\ ${ }^{2}$ Escola de Engenharia, Universidade Federal de Minas Gerais, \\ francisco@dees.ufmg.br \\ ${ }^{3}$ Escola de Engenharia, Universidade Federal de Minas Gerais, \\ caldas@dees.ufmg.br
}

\section{Experimental study of the Oriented Strand Board (OSB) connection with steel studs of the Light Steel Framing Construction System}

\begin{abstract}
Resumo
Esta pesquisa tem por objetivo a análise da ligação entre os painéis de OSB e o reticulado metálico do sistema light steel framing (LSF) com parafusos autobrocantes e autoatarraxantes. Através dos ensaios de forca-deslizamento, os resultados obtidos possibilitarão a realização de análises paramétricas visando à proposição de soluções analíticas para a quantificação da contribuição dos painéis de OSB na estabilização do sistema estrutural do LSF, com ou sem o uso do contraventamento de aço. Para isso, além dos 12 corpos de prova produzidos e ensaiados por Possas (2015), mais experimentos complementares foram feitos com 9 CP's. Com a análise do resultado dos 21 CP's, observou-se que os valores, por ligação, da força máxima, da rigidez, da energia dissipada e da ductilidade foram influenciados pela espessura dos painéis de OSB, pela quantidade de parafusos e pelo espaçamento axial entre si.
\end{abstract}

Palavras-chave: Lascas de madeira orientadas (OSB), Contraventamento, Parafuso autobrocante e auto-atarraxante, Cisalhamento.

\begin{abstract}
This research has the purpose of analyzing the connection between the OSB and the frame steel studs of the light steel framing (LSF) construction system with self-drilling and selftapping screws. Through the strength-slip tests, the results obtained will allow the performance of parametric analyzes focusing at the proposition of analytical solutions for the quantification of the contribution of the OSB in the stabilization of the LSF structural system, with or without the use of steel bracing. For this, in addition to the 12 specimens produced and tested by Possas (2015), more complementary experiments were done with 9 specimens. With the analysis of the results of the 21 test specimens, it was observed that the values, by connection, of the maximum load, the stiffness, the dissipated energy and the ductility were influenced by the OSB thickness, the number of screws and the axial spacing between them.
\end{abstract}

Keywords: Oriented Strand Board (OSB), Bracing, Self-drilling and self-tapping screws, Shear. 


\section{Introdução}

O sistema LSF se resume a uma composição de painéis reticulados de aço galvanizado de perfis formados a frio (PFF) trabalhando em conjunto com placas de diferentes materiais, tais como as placas cimentícias e os painéis de lascas orientadas de madeira, internacionalmente denominadas de Oriented Strand Board (OSB), constituindo assim a estrutura de uma construção à seco. Segundo Rodrigues (2016), o sistema estrutural total de uma edificação em LSF pode ser dividido em dois grupos de subsistemas, os verticais e os horizontais, sendo que a sua estabilidade global é garantida pelo sistema de contraventamento.

Okasha (2004), Fiorino et al. (2007), Vieira et al. (2009), Peterman et al. (2014), luorio et al. (2014) e Jihong et al. (2016) realizaram ensaios de cisalhamento com painéis de OSB, parafusos e perfis de aço e observaram que os valores da força resistente ao cisalhamento, da rigidez elástica, da energia dissipada e da ductilidade da ligação são influenciados pela espessura dos painéis, pela distância de borda do painel até o eixo dos parafusos, pela distância axial entre os parafusos, pela quantidade de parafusos e pela espessura dos perfis de aço.

Possas (2015) realizou análises experimentais adaptados aos ensaios do tipo Push-Test, conforme a norma EN 1994-1-1:2004, para verificar o comportamento da ligação do subsistema de parede constituído por painéis de OSB, parafusos e montantes de borda (Figura 1). 12 CP's foram fabricados variando a espessura dos painéis de OSB, a dimensão da alma do montante de aço, o espaçamento axial entre os montantes e o espaçamento axial entre os parafusos (Tabela 1 ). Os dados de ensaio obtidos por Possas (2015) foram usados e processados para determinar os valores da força máxima $\left(P_{\text {máx }}\right)$, da rigidez elástica $\left(k_{e}\right)$, da energia dissipada $(A)$ e da ductilidade $(\mu)$ da ligação do modelo 1 apresentado na presente pesquisa. 


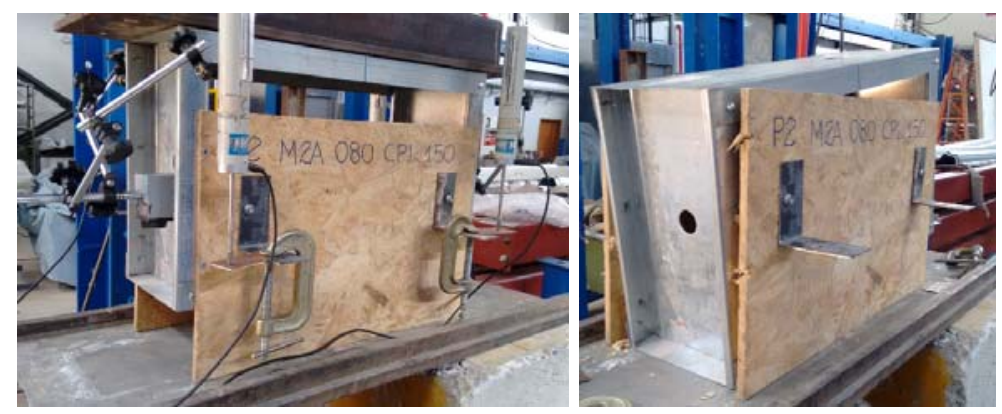

Figura 1 - Modelo 1-S1 CP1 antes e depois do ensaio (Possas, 2015).

Como nomenclatura desse modelo, tem-se: a série com o seu número (Sx), o montante com a sua quantidade ( $\mathrm{Mx}$ ), a espessura nominal do painel de OSB (tosB como A e B), a espessura nominal do perfil de aço $\left(t_{n}\right)$, a dimensão da alma do perfil $\left(b_{w}\right)$, o espaçamento axial entre os montantes $\left(e_{m}\right)$, o espaçamento axial entre os parafusos $\left(e_{p}\right)$, a quantidade de parafusos $\left(Q_{p}\right)$ e a quantidade dos corpos de prova $\left(Q_{c p}\right)$.

Tabela 1 - Parâmetros relativos aos corpos de prova do modelo 1 ensaiado (montantes de borda).

\begin{tabular}{|c|c|c|c|c|c|c|c|}
\hline \multicolumn{2}{|c|}{ Nomenclatura } & tosB & $\stackrel{t_{n}}{t m m}$ & $b_{w} ; e_{m}$ & $\underset{(m p)}{e_{p}}$ & $Q_{p}$ & $Q_{c p}$ \\
\hline S1 M2-A-200-600-150 & Modelo 1-S1 & \multirow{2}{*}{9,5} & \multirow{4}{*}{0,95} & $200 ; 600$ & 150 & \multirow{2}{*}{8} & 3 \\
\hline S2 M2-A-090-400-300 & Modelo 1-S2 & & & $90 ; 400$ & 300 & & 3 \\
\hline S3 M2-B-090-600-150 & Modelo 1-S3 & \multirow[b]{2}{*}{11,1} & & $90 ; 600$ & \multirow{2}{*}{150} & \multirow{2}{*}{12} & 3 \\
\hline S4 M2-B-200-600-150 & Modelo 1-S4 & & & $200 ; 600$ & & & 3 \\
\hline
\end{tabular}

Além do processamento dos dados de ensaio obtidos por Possas, foram realizadas um estudo experimental complementar com o modelo 2 que era constituído de 9 CP's. A principal diferença entre os modelos 1 e 2 está vinculada ao número de montante nos corpos de prova. Os CP's do modelo 1 foram fabricados com dois montantes para representar os montantes de bordas do painel de parede no sistema construtivo light steel framing. Os CP's do modelo 2 foram fabricados com um montante para representar o montante intermediário do painel de parede no mesmo sistema.

Os resultados obtidos nesta pesquisa servirão de base para a realização de análises paramétricas visando à proposição de soluções analíticas para a quantificação da contribuição dos painéis de OSB na estabilização do sistema estrutural do LSF, com ou sem o uso do contraventamento de aço. Com o desenvolvimento do subsistema de contraventamento com o emprego dos painéis de OSB para o sistema LSF, painéis essas já presentes no sistema como elementos de revestimento do reticulado metálico 
para a formação das paredes, além de significar uma inovação tecnológica para a construção civil, torna possível obter edificações com custo reduzido, mantendo a qualidade, a durabilidade e a estabilidade exigidas pelas normas brasileiras aplicáveis. E também atendendo aos critérios da sustentabilidade da construção metálica.

\section{Estudo experimental complementar}

Neste item serão apresentados detalhamentos sobre o estudo experimental complementar realizado com os corpos de prova do modelo 2 .

\subsection{Materiais}

Para a análise do sistema LSF, considerando a placa de revestimento como parte da estrutura, é importante considerar a ação conjunta do reticulado metálico, da placa de revestimento e dos parafusos de fixação. O estudo da interface perfil de aço e placa tem importância fundamental, pois é nesta região que atuam as forças de cisalhamento, as quais são transmitidas, pelos parafusos de fixação, do reticulado metálico para as placas de vedação. Os parafusos de fixação são responsáveis por garantir a ação conjunta entre esses dois elementos do subsistema de parede.

Para a fabricação dos corpos de prova deste modelo 2, foi necessário o uso de painéis de OSB, de perfis formados a frio (PFF) e de parafusos autobrocantes e autoatarraxantes.

Os painéis de OSB foram fabricadas pela empresa LP com as dimensões nominais de 9,5 e 11,1 mm (espessuras); $1.200 \mathrm{~mm}$ (largura) e $2.400 \mathrm{~mm}$ (altura). Os montantes foram feitos de perfis formados a frio com seção $U$ enrijecida (Ue) nas dimensões nominais $b_{w}$ referente à alma (90 e $\left.200 \mathrm{~mm}\right), b_{f}$ referente às mesas $(40 \mathrm{~mm})$ e D referente aos enrijecedores $(10 \mathrm{~mm})$. As guias foram executadas com perfis de seção $U$ simples (U) nas dimensões nominais $b_{w}$ iguais a 92 e $202 \mathrm{~mm}$ e $b_{f}$ igual a $38 \mathrm{~mm}$ (mesas). A bobina foi produzida pela Usiminas com espessura nominal $\left(t_{n}\right)$ igual a 0,95 $\mathrm{mm}$. As ligações entre os perfis formados a frio foram feitas com parafusos cabeça lentilha e ponta broca da marca Ancora com 4,2 mm de diâmetro e 12,7 mm de comprimento. As ligações entre os painéis de OSB e o reticulado metálico foram feitas com parafusos cabeça trombeta e ponta broca da marca Ciser com 4,2 mm de diâmetro e $32 \mathrm{~mm}$ de comprimento. 
Foram estabelecidos 3 CP's para compor cada série e a posição do montante para a definição dos dois tipos de modelos (1 e 2). As séries dependiam da espessura nominal do painel de OSB, da dimensão nominal da alma do montante, do espaçamento axial entre os montantes e do espaçamento axial entre os parafusos.

\subsection{Características dos corpos de prova do modelo 2}

O modelo 2 era composto por 9 CP's, e cada um era constituído de um montante, de dois painéis e de parafusos de fixação (Tabela 2).

Tabela 2 - Parâmetros relativos aos corpos de prova do modelo 2 ensaiado (montante intermediário).

\begin{tabular}{|c|c|c|c|c|c|c|c|}
\hline \multicolumn{2}{|c|}{ Nomenclatura } & $\begin{array}{c}\text { tosB } \\
(\mathrm{mm})\end{array}$ & $t_{n}(m m)$ & $\begin{array}{c}\mathbf{b}_{\mathrm{w}} \\
(\mathrm{mm})\end{array}$ & $\underset{(\mathrm{mm})}{\mathbf{e}_{\mathbf{p}}}$ & $Q_{p}$ & $Q_{c p}$ \\
\hline S1 & Modelo 2-S1 & \multirow{2}{*}{11,1} & \multirow{3}{*}{0,95} & 200 & \multirow{3}{*}{150} & \multirow{3}{*}{10} & 3 \\
\hline S2 & Modelo 2-S2 & & & \multirow{2}{*}{90} & & & 3 \\
\hline S3 & Modelo 2-S3 & 9,5 & & & & & 3 \\
\hline
\end{tabular}

\subsection{Procedimento de ensaio dos corpos de prova}

Para realizar esses ensaios de cisalhamento, usou-se um quadro de força que era composto de um cilindro hidráulico de dupla ação com capacidade de 50 toneladas; dois DT's com capacidade de medição de 100 mm; um aquisitor de dados Lynx AC 2122 com o software AqDados 7.02; um anel dinamométrico com capacidade de 50.000 kgf; uma bomba hidráulica manual com 700 bar como máxima pressão de trabalho.

Com adaptações a partir das prescrições da norma européia BS EN 1994-1-1:2004, o procedimento de ensaio dos 9 CP's foi realizado em duas principais etapas. Sendo na primeira etapa, carregando continuamente o primeiro CP de cada série até a sua ruptura. E, a segunda etapa, aplicada aos demais corpos de prova da mesma série, foi composta por três fases de carregamento: inicialmente, foram aplicados incrementos de força até atingir $5 \%$ da força máxima obtida no primeiro $\mathrm{CP}$ e esperou-se por 3 minutos para que o subsistema se estabilizasse; carregou-se novamente o CP até alcançar $40 \%$ da mesma força máxima e esperou-se por 3 minutos; voltou-se ao carregamento progressivo até a força máxima e esperou-se mais uma vez durante 3 minutos. 


\section{Resultados obtidos na experimentação complementar}

Neste item apresenta-se os resultados obtidos sem análise estatística (Tabela 3). $P_{t}$ é igual à força total alcançada pelo corpo de prova durante o ensaio enquanto $\mathrm{P}_{\text {máx }}$ é igual a força máxima alcançada por cada ligação que compõe o corpo de prova.

Tabela 3 - Resultados relativos ao ensaio dos corpos de prova do modelo 2.

\begin{tabular}{|c|c|c|c|c|c|c|c|}
\hline Nomenclatura & $\mathbf{P}_{\mathbf{t}} \mathbf{( N )}$ & $\mathbf{P}_{\text {máx }} \mathbf{( N )}$ & $\mathbf{P}_{\mathbf{e}} \mathbf{( N )}$ & $\begin{array}{c}\boldsymbol{\delta}_{\mathbf{e}} \\
\mathbf{( m m})\end{array}$ & $\mathbf{k e}(\mathbf{N} / \mathbf{m m})$ & $\mathbf{A}(\mathbf{N} . \mathbf{m m})$ & $\boldsymbol{\mu}$ \\
\hline S1 CP1 & 23.012 & 2.301 & 920 & 0,05 & 17.960 & 5.120 & 29 \\
\hline S1 CP1a & 28.238 & 2.824 & 1.129 & 0,69 & 1.632 & 12.697 & 4 \\
\hline S1 CP2 & 19.085 & 1.908 & 763 & 0,04 & 17.191 & 3.549 & 29 \\
\hline S1 CP3 & 27.682 & 2.768 & 1.107 & 0,09 & 12.269 & 20.423 & 51 \\
\hline S2 CP1 & 25.269 & 2.527 & 1.011 & 0,41 & 2.487 & 19.360 & 12 \\
\hline S2 CP2 & 21.342 & 2.134 & 854 & 0,65 & 1.312 & 13.638 & 6 \\
\hline S3 CP1 & 26.012 & 2.601 & 1.040 & 0,19 & 5.381 & 18.250 & 20 \\
\hline S3 CP2 & 26.599 & 2.660 & 1.064 & 0,52 & 2.027 & 15.189 & 6 \\
\hline S3 CP3 & 19.488 & 1.949 & 779 & - & - & 5.604 & - \\
\hline
\end{tabular}

No ensaio do CP3 da série 2, o software de aquisição de dados não foi iniciado por engano provocando a não obtenção dos seus dados.

No ensaio do CP3 da série 3, o carregamento muito rápido provocou um erro inicial nos DT's impossibilitando a determinação positiva dos valores da rigidez e da ductilidade.

\section{Análise dos resultados}

Neste item apresenta-se o modo de análise dos dados, as discussões dos resultados obtidos com os modelos 1 e 2, a influência dos parâmetros de fabricação dos corpos de prova desses modelos sobre esses resultados e a comparação entre esses mesmos com os resultados das bibliografias citadas.

\subsection{Modo de análise dos dados obtidos a partir dos corpos de prova do modelo 2}

Seguindo as prescrições das normas ECCS-1985, AISI Research Report RP00-6 e AISI S917-17, foram determinados o valor, por ligação, da rigidez inicial ( $\left.k_{e}\right)$ pela Equação (1), da energia dissipada (A) e da ductilidade ( $\mu$ ) pela Equação (2), de cada CP.

Além da curva de força versus deslocamento entre o painel de OSB e o perfil de aço, foi também elaborada a curva de EEEP (Equivalent Energy Elastic-Plastic: curva elastoplástica da energia equivalente). Essa curva mostra como uma ligação ideal e 
perfeitamente elasto-plástica desenvolveria e dissiparia uma quantidade equivalente de energia conforme o modelo realmente testado.

$$
\begin{gathered}
k_{e}=P_{e} / \delta_{e} \\
\mu=\left(\delta_{u} / \delta_{y}\right)>1 \\
P_{y}=\left(-\delta_{u} \pm\left(\delta_{u}{ }^{2}-\left(2 A / k_{e}\right)\right)^{0,5}\right) /\left(1 / k_{e}\right)
\end{gathered}
$$

Onde $P_{\operatorname{máx}}(\mathrm{N})$ é a força máxima alcançada pela ligação e $\delta_{\mathrm{e}}(\mathrm{mm})$ é o deslocamento

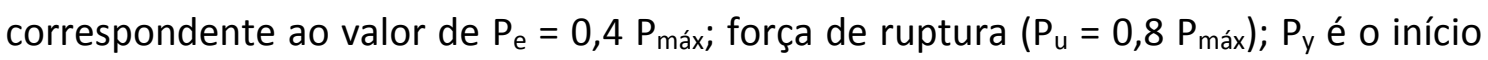
de escoamento que é determinado pela Equação (3). Para a interpretação dos dados experimentais obtidos, foi determinado o coeficiente de variação $\left(C_{v}\right)$ pela Equação (4).

$$
C_{v}=\left(D P / x_{m}\right) * 100
$$

De um modo geral, tem-se: $15 \% \geq C_{v}$ : baixa dispersão (resultados homogêneos); $15 \%<$ $C_{v}<30 \%$ : média dispersão; $C_{v} \geq 30$ \%: alta dispersão (resultados heterogêneos). DP é o desvio padrão e $X_{m}$ a média dos valores. Essa forma de análise também foi aplicada aos corpos de prova do modelo 1.

O CP1 da série 1 (Figura 2) alcançou um $\mathrm{P}_{\text {máx }}$ igual a 2.301,20 N com um deslocamento de 2,73 mm, um $P_{y}$ igual a 1.787,99 $\mathrm{N}$ com um deslocamento de $0,10 \mathrm{~mm}$ e um $\mathrm{Pu}_{\mathrm{u}}$ igual $1.840,96 \mathrm{~N}$ com um deslocamento correspondente de 2,91 mm. Durante os ensaios, o início dos estalos foi com aproximadamente $14.837,46 \mathrm{~N}$ com a rotação dos parafusos e o ensaio foi interrompido por causa da flambagem na base dos painéis de OSB com os parafusos inferiores caminhando para o Pull-over. Por causa dessa flambagem, as bases dos painéis dos demais CP's foram cortadas mantendo a sua altura com $50 \mathrm{~mm}$ (distância entre a guia inferior e a base dos painéis). 

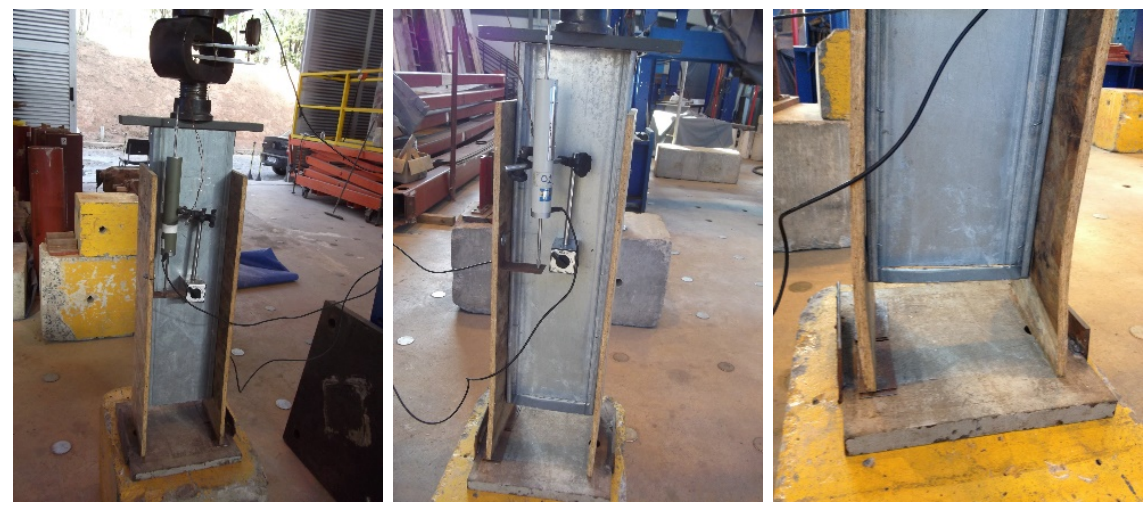

Figura 2 - Modelo 2-S1 CP1 antes e depois do ensaio.

O CP1 da série 2 alcançou um $P_{\text {máx }}$ igual a 2.526,95 $\mathrm{N}$ com um deslocamento de 7,94 $\mathrm{mm}$, um $\mathrm{P}_{\mathrm{y}}$ igual a $2.052,91 \mathrm{~N}$ com um deslocamento de $0,83 \mathrm{~mm}$ e um $\mathrm{Pu}$ igual 2.021,56 N com um deslocamento correspondente de 9,84 mm. Durante os ensaios, o início dos estalos foi com aproximadamente $18.328,63 \mathrm{~N}$ com a rotação de todos os parafusos e a ruptura do CP ocorreu por Pull-over e por plastificação no topo do perfil de aço (Figura 3).
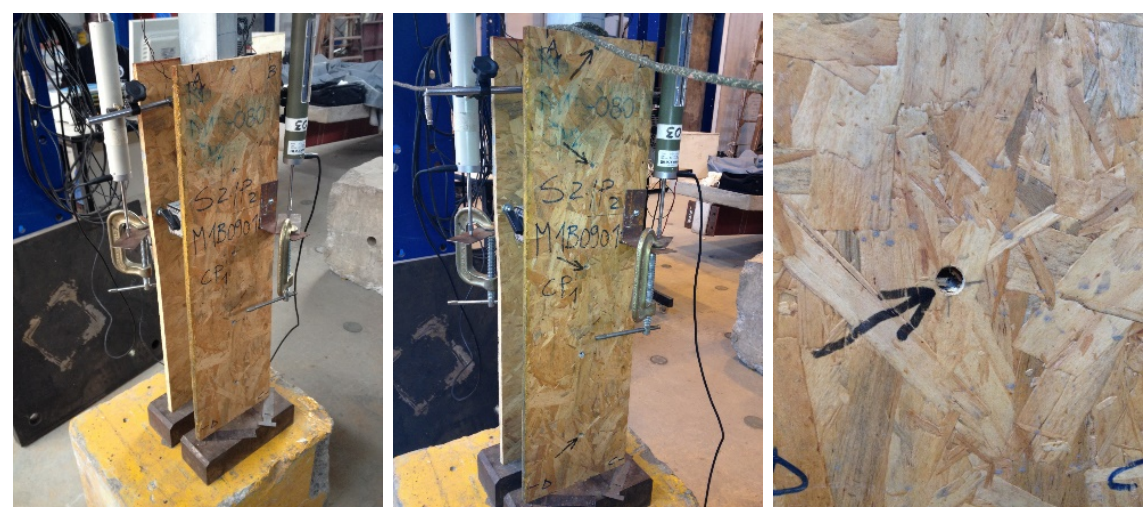

Figura 3 - Modelo 2-S2 CP1 antes e depois do ensaio.

O CP1 da série 3 alcançou um $P_{\text {máx }}$ igual a 2.601,17 N com um deslocamento de 6,43 $\mathrm{mm}$, um $\mathrm{P}_{\mathrm{y}}$ igual a $2.260,23 \mathrm{~N}$ com um deslocamento de $0,42 \mathrm{~mm}$ e um $\mathrm{P}_{\mathrm{u}}$ igual 2.080,94 $\mathrm{N}$ com um deslocamento correspondente de $8,28 \mathrm{~mm}$. Esse $\mathrm{CP}$ tinha $\mathrm{O}$ penúltimo parafuso do painel P2 de OSB rotacionado levemente. Durante os ensaios, o início dos estalos foi com aproximadamente $21.819,80 \mathrm{~N}$ com a rotação de todos os parafusos e a ruptura do CP ocorreu com o encaminhamento da ligação para o Pullover (Figura 4). 

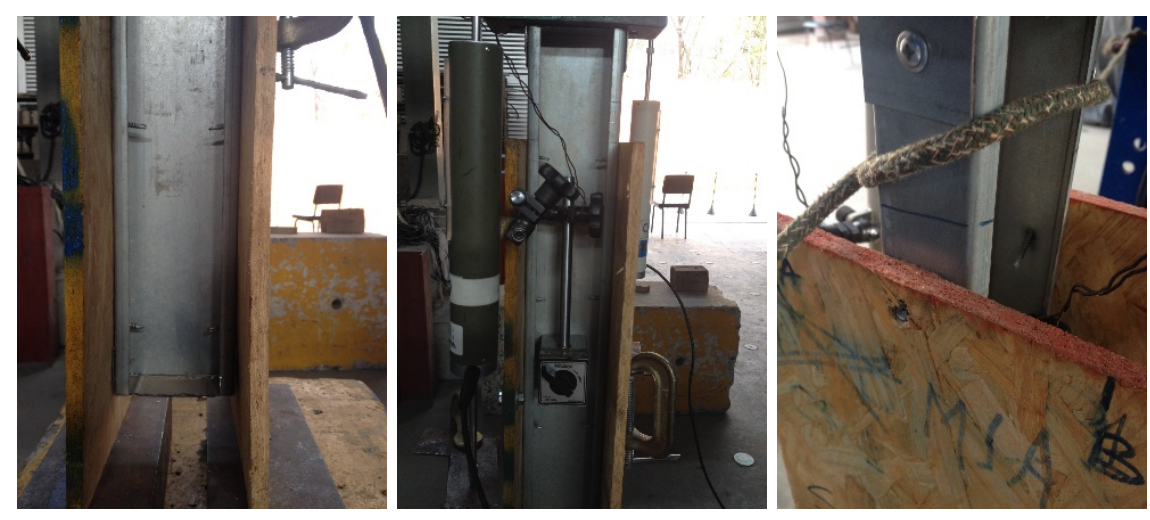

Figura 4 - Modelo 2-S3 CP1 antes e depois do ensaio.

\subsection{Discussões dos resultados obtidos a partir do processamento dos dados de ensaio dos corpos de prova do modelo 1}

Por causa do erro de fabricação dos CP's 2 e 3 da série 1 do modelo 1 (Tabela 4), considerou-se, para a análise posterior da influência dos parâmetros, somente os valores por ligação, da força máxima $\left(P_{\text {máx }}\right)$, da rigidez $\left(k_{e}\right)$, da energia dissipada $(A)$ e da ductilidade $(\mu)$ do CP1.

Tabela 4 - Resultados relativos ao ensaio dos corpos de prova do modelo 1 (S1).

\begin{tabular}{|c|c|c|c|c|c|c|c|}
\hline Nomenclatura & $P_{t}(N)$ & $P_{\text {máx }}(\mathrm{N})$ & $P_{e}(N)$ & $\begin{array}{c}\delta_{e} \\
(\mathrm{~mm})\end{array}$ & ke $(\mathrm{N} / \mathrm{mm})$ & $A(N . m m)$ & $\mu$ \\
\hline S1 CP1 & 12.620 & 1.577 & 631 & 0,20 & 3.133 & 8.444 & 16 \\
\hline S1 CP2 & 6.540 & 817 & 327 & 0,09 & 3.732 & 1.300 & 10 \\
\hline S1 CP3 & 13.876 & 1.734 & 694 & 0,24 & 2.946 & 6.430 & 9 \\
\hline \multicolumn{2}{|l|}{$x_{m}$} & - & & - & - & - \\
\hline \multicolumn{2}{|c|}{$\mathrm{C}_{\mathrm{v}}(\%)$} & - & & & - & - & - \\
\hline
\end{tabular}

O maior valor de $\mathrm{P}_{\text {máx }}$ foi obtido pelo CP3, o de $k_{e}$ pelo CP2 e os maiores valores de A e de $\mu$ foram obtidos pelo CP1. O maior valor de $k_{e}$ foi obtido pelo CP2 por causa do seu baixo valor de deslocamento $\left(\delta_{\mathrm{e}}\right)$ apesar de ter registrado o menor valor de $\mathrm{P}_{\text {máx }}$ (Figura 5).

Com a série 2 do modelo 1 (

Tabela 5), $P_{\text {máx }}$ teve seu valor de $C_{v}$ inferior a $15 \%$, o que demonstra a maior confiabilidade e homogeneidade dos resultados. $O C_{v}$ a partir dos valores de $k_{e}$ foi registrado entre 15 e $30 \%$, o que caracteriza a média dispersão dos resultados. Com os valores de $A$ e de $\mu$, tem-se um $C_{v}$ acima de 30\% demonstrando a alta dispersão e a heterogeneidade dos resultados. Essa alta dispersão se deve aos maiores e baixos valores de $\mathrm{A}$ e de $\mu$ alcançados pelos CP's 2 e 3 . 


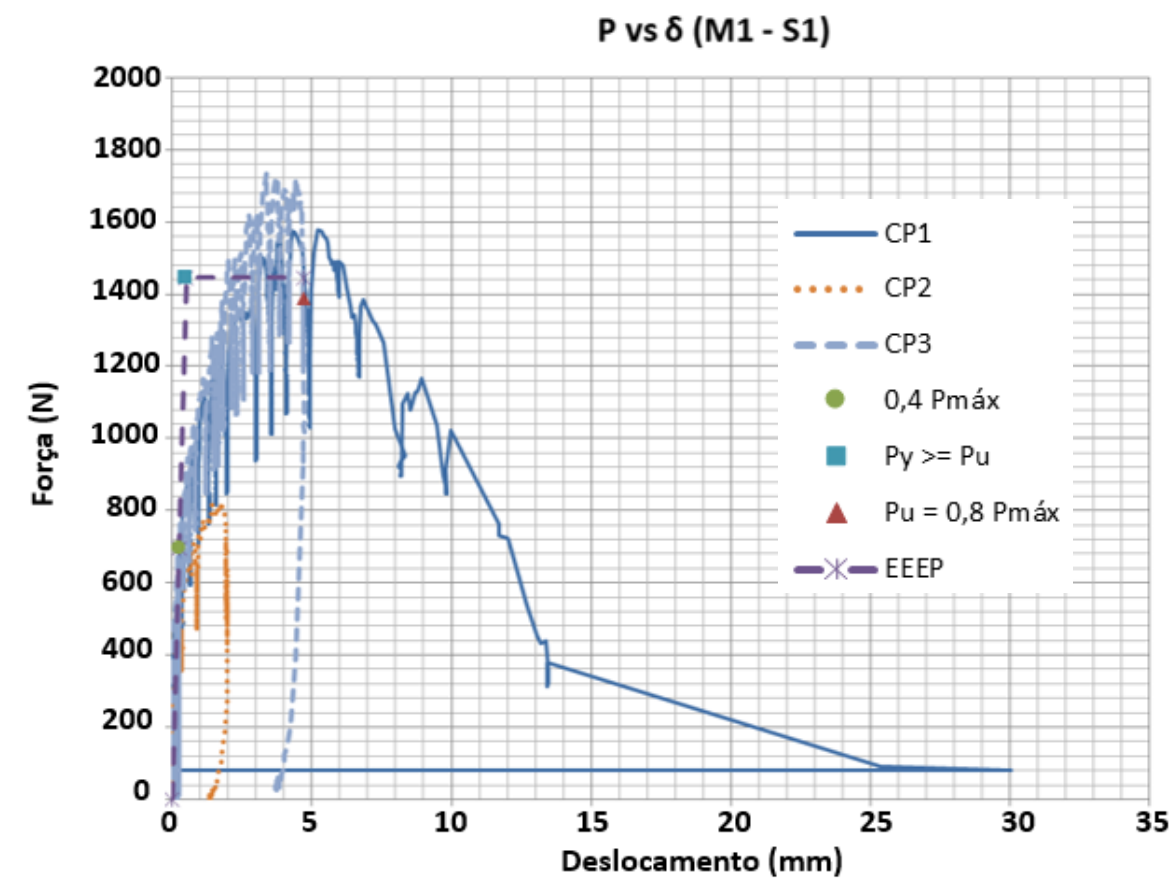

Figura 5 - Gráfico força versus deslocamento dos corpos de prova do modelo 1 (S1).

Tabela 5 - Resultados relativos ao ensaio dos corpos de prova do modelo 1 (S2).

\begin{tabular}{|c|c|c|c|c|c|c|c|}
\hline Nomenclatura & $P_{t}(N)$ & $P_{\text {máx }}(\mathrm{N})$ & $P_{e}(N)$ & $\begin{array}{c}\delta_{e} \\
(\mathrm{~mm})\end{array}$ & ke $(\mathrm{N} / \mathrm{mm})$ & $A(N . m m)$ & $\mu$ \\
\hline S2 CP1 & 12.694 & 1.587 & 635 & 0,04 & 15.210 & 9.424 & 76 \\
\hline S2 CP2 & 11.709 & 1.464 & 585 & 0,04 & 15.495 & 14.210 & 127 \\
\hline S2 CP3 & 11.734 & 1.467 & 587 & 0,06 & 9.205 & 4.950 & 30 \\
\hline \multicolumn{2}{|l|}{$\mathbf{x}_{\mathrm{m}}$} & 1.506 & \multirow{2}{*}{\multicolumn{2}{|c|}{ _ }} & 13.303 & 9.528 & 78 \\
\hline \multicolumn{2}{|c|}{$C_{v}(\%)$} & 7 & & & 27 & 49 & 62 \\
\hline
\end{tabular}

O maior valor de $\mathrm{P}_{\text {máx }}$ foi obtido pelo CP1 e os maiores valores de $k_{e}$, de $A$ e de $\mu$ foram obtidos pelo CP2. O maior valor de $k_{e}$ se deve aos baixos valores de $P_{e}$ e de $\delta_{e}$ (Figura $6)$.

Excluindo o valor de $k_{e}$ do CP3 e os valores de A e de $\mu$ dos CP's 2 e 3, obtém-se o valore médio de $k_{e}$ igual a $15.352,64 \mathrm{~N} / \mathrm{mm}$ com o seu valor de $C_{v}$ inferior a $15 \%$, o que demonstra a maior confiabilidade e homogeneidade dos resultados. 


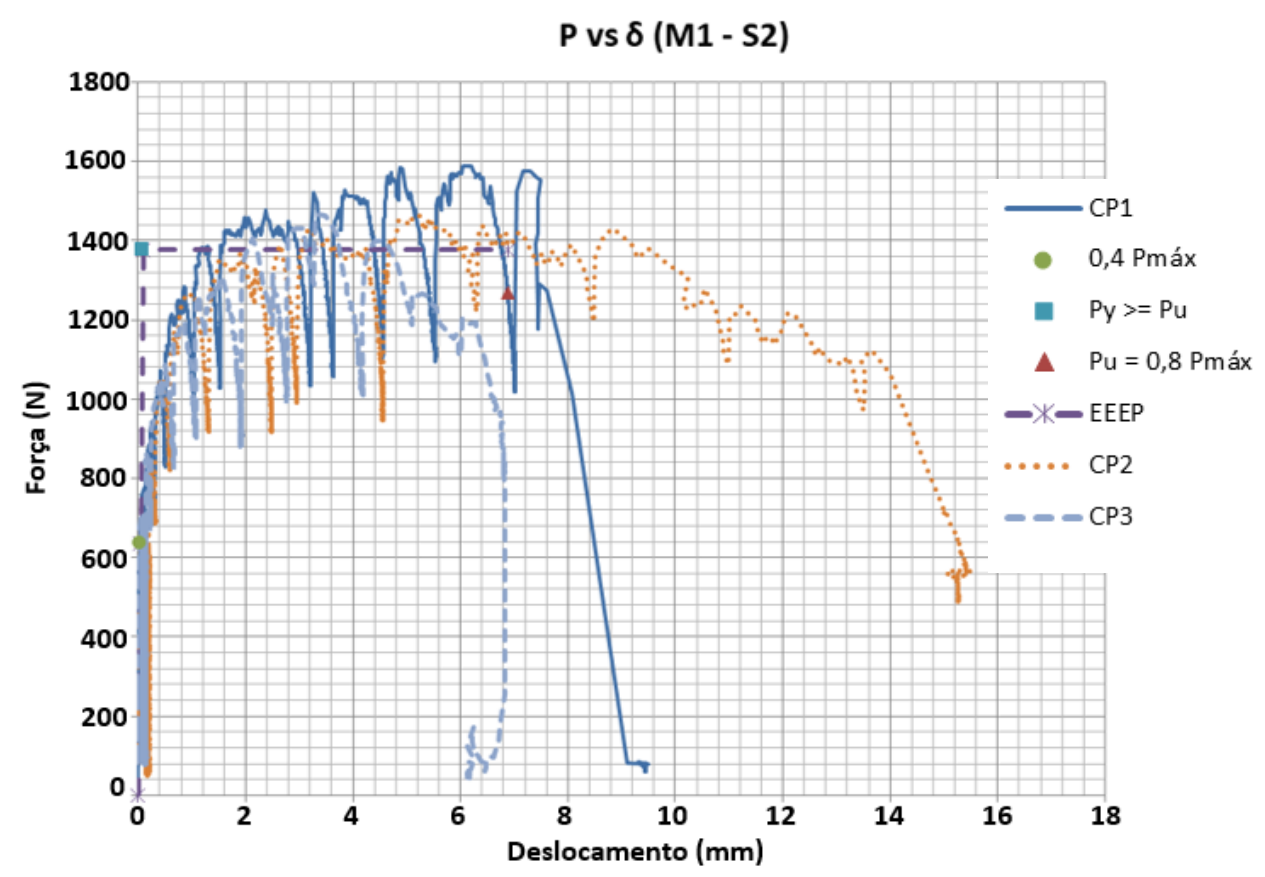

Figura 6 - Gráfico força versus deslocamento dos corpos de prova do modelo 1 (S2).

Na série 3 do modelo 1 (Tabela 6), $P_{\text {máx }}$ teve o seu valor de $C_{v}$ inferior a $15 \%$, o que demonstra a maior confiabilidade e homogeneidade dos resultados. Com os valores de $k_{e}$, de $A$ e de $\mu$, tem-se um $C_{v}$ acima de 30\% demonstrando a alta dispersão e a heterogeneidade dos resultados. Essa alta dispersão se deve aos altos valores de $k_{e}$, de A e de $\mu$ alcançados pelo CP3.

Tabela 6 - Resultados relativos ao ensaio dos corpos de prova do modelo 1 (S3).

\begin{tabular}{|c|c|c|c|c|c|c|c|}
\hline Nomenclatura & $P_{t}(N)$ & $P_{\text {máx }}(N)$ & $P_{e}(N)$ & $\begin{array}{c}\delta_{e} \\
(\mathrm{~mm})\end{array}$ & ke (N/mm) & $A(N . m m)$ & $\mu$ \\
\hline S3 CP1 & 19.365 & 1.614 & 645 & 0,47 & 1.365 & 14.747 & 10 \\
\hline S3 CP2 & 21.039 & 1.753 & 701 & 0,40 & 1.743 & 14.362 & 11 \\
\hline S3 CP3 & 17.913 & 1.493 & 597 & 0,02 & 26,703 & 6.419 & 104 \\
\hline \multicolumn{2}{|l|}{$\mathbf{x}_{\mathrm{m}}$} & 1.620 & & 9.937 & 11.843 & 42 \\
\hline \multicolumn{2}{|c|}{$\mathrm{C}_{\mathrm{v}}(\%)$} & 8 & & & 146 & 39 & 129 \\
\hline
\end{tabular}

O maior valor de $\mathrm{P}_{\text {máx }}$ foi obtido pelo $\mathrm{CP} 2$, o de $\mathrm{A}$ pelo CP1 e os maiores valores de $\mathrm{k}_{\mathrm{e}} \mathrm{e}$ de $\mu$ foram obtidos pelo CP3. O maior valor de $k_{e}$ se deve aos baixos valores de $P_{e}$ e de $\delta_{\text {e }}$ (Figura 7). 


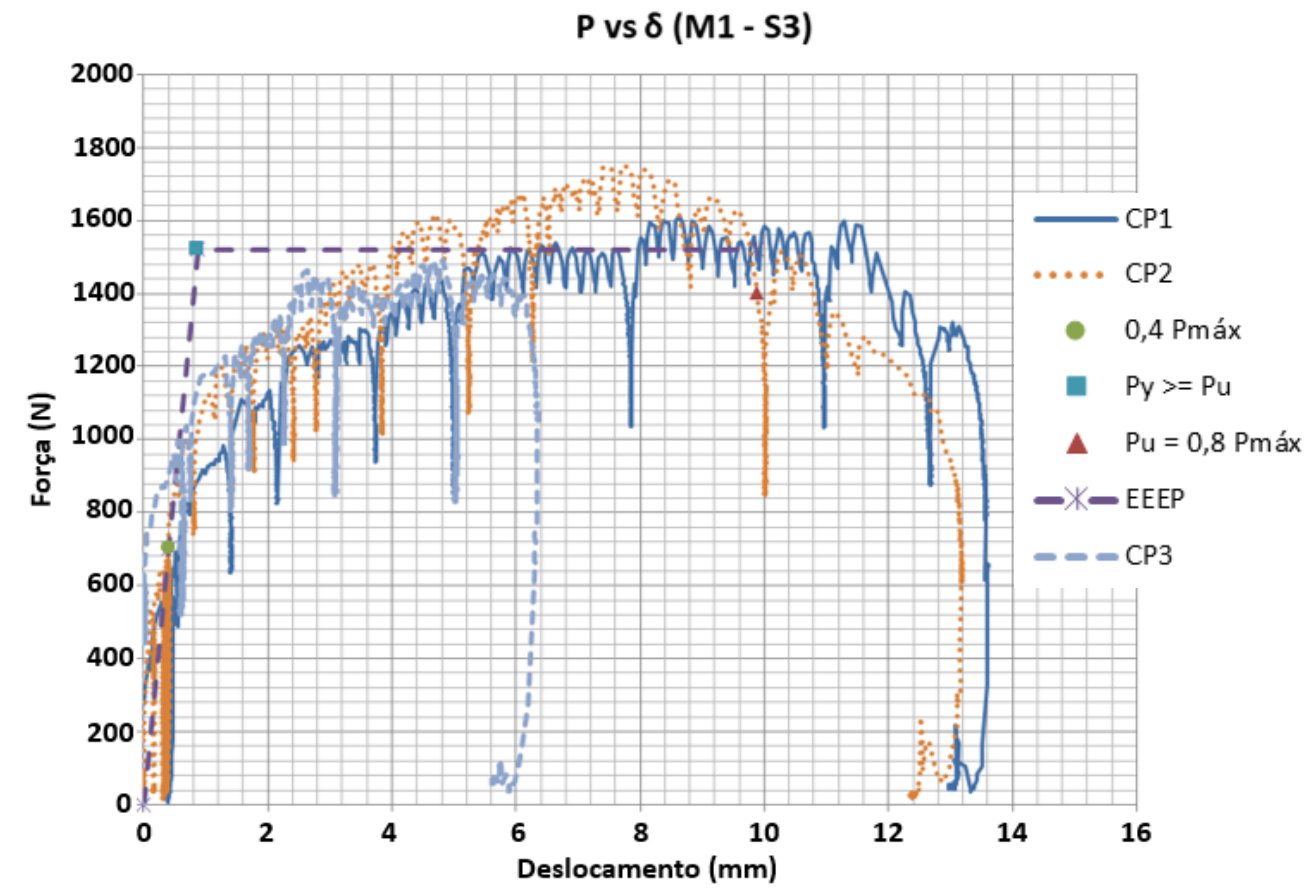

Figura 7 - Gráfico força versus deslocamento dos corpos de prova do modelo 1 (S3).

Excluindo os valores de $k_{e}$, de $A$ e de $\mu$ do CP3, obtém-se os seus novos valores médios, respectivamente iguais a $1.554,06 \mathrm{~N} / \mathrm{mm}, 14.554,76 \mathrm{~N} \cdot \mathrm{mm}$ e $10,93 \mathrm{com}$ os seus valores de $C_{v}$ inferiores a 15\%, o que demonstra a maior confiabilidade e homogeneidade dos resultados. O $\mathrm{C}_{\mathrm{v}}$ a partir dos valores de $\mathrm{k}_{\mathrm{e}}$ ficou entre 15 e $30 \%$ caracterizando a média dispersão dos resultados.

Na série 4 do modelo 1 (Tabela 7), $P_{\text {máx }}$ teve o seu valor de $C_{v}$ inferior a $15 \%$, o que demonstra a maior confiabilidade e homogeneidade dos resultados. $O C_{v}$ a partir dos valores de A foi obtido entre 15 e $30 \%$ caracterizando a média dispersão dos resultados. Com os valores de $\mathrm{k}_{\mathrm{e}}$ e $\mu$, tem-se um $\mathrm{C}_{v}$ acima de $30 \%$ demonstrando a alta dispersão e a heterogeneidade dos resultados. Essa alta dispersão se deve aos altos valores de $k_{e}$ e de $\mu$ alcançados pelo CP2.

Tabela 7 - Resultados relativos ao ensaio dos corpos de prova do modelo 1 (S4).

\begin{tabular}{|c|c|c|c|c|c|c|c|}
\hline Nomenclatura & $P_{t}(N)$ & $P_{\text {máx }}(N)$ & $P_{e}(N)$ & $\begin{array}{c}\delta_{\mathrm{e}} \\
(\mathrm{mm})\end{array}$ & ke (N/mm) & A (N.mm) & $\mu$ \\
\hline S4 CP1 & 22.491 & 1.874 & 750 & 0,38 & 1.991 & 14.304 & 13 \\
\hline S4 CP2 & 21.605 & 1.800 & 720 & 0,08 & 8.563 & 10,848 & 40 \\
\hline S4 CP3 & 22.712 & 1.893 & 757 & 0,41 & 1.830 & 15.409 & 11 \\
\hline \multicolumn{2}{|c|}{$x_{m}$} & 1.856 & & 4.128 & 13.520 & 21 \\
\hline \multicolumn{2}{|c|}{$C_{v}(\%)$} & 3 & & & 93 & 18 & 75 \\
\hline
\end{tabular}


Os maiores valores de $\mathrm{P}_{\text {máx }}$ e de $\mathrm{A}$ foram obtidos pelo $\mathrm{CP} 3$ e os de $k_{\mathrm{e}}$ e de $\mu$ pelo $\mathrm{CP} 2$. $\mathrm{O}$ maior valor de $k_{e}$ se deve aos baixos valores de $\mathrm{P}_{\mathrm{e}}$ e de $\delta_{\mathrm{e}}$ (Figura 8).

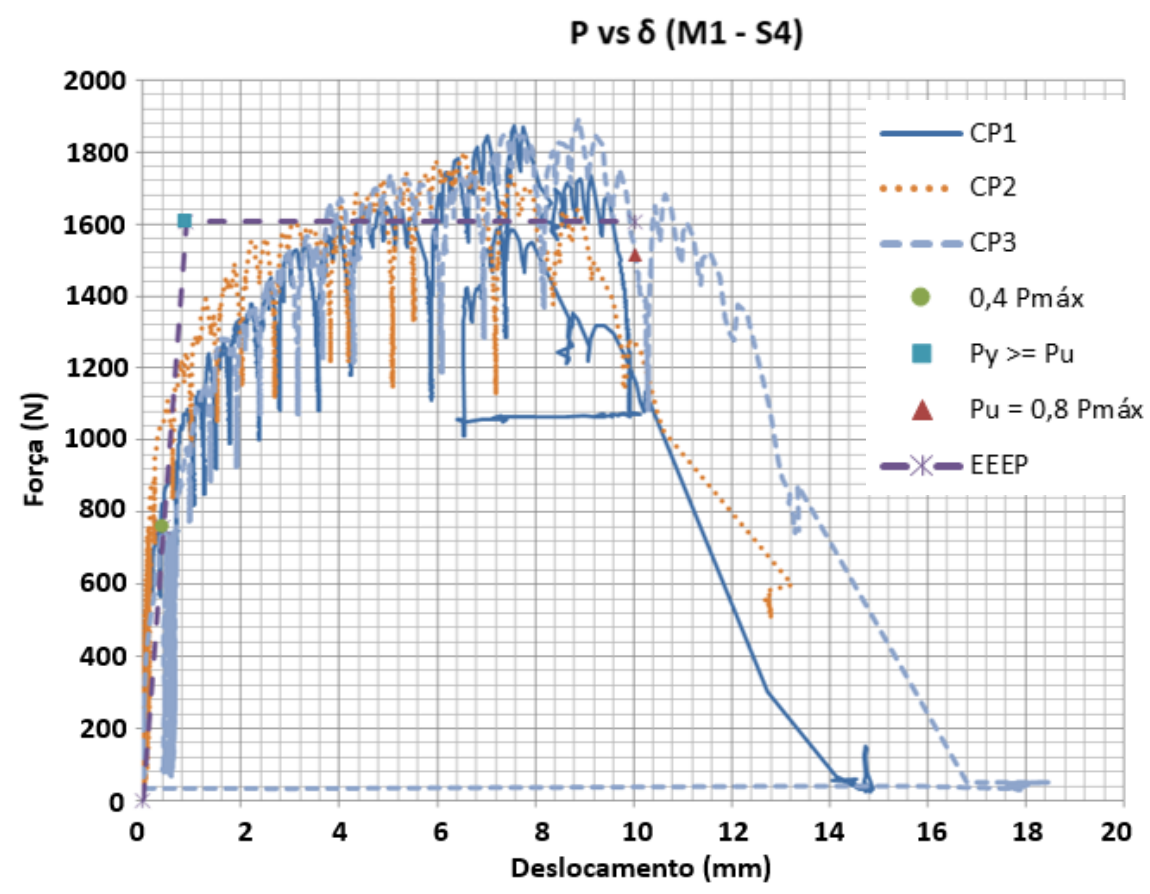

Figura 8-Gráfico força versus deslocamento dos corpos de prova do modelo 1 (S4).

Excluindo os valores de $k_{\mathrm{e}}$, de $\mathrm{A}$ e de $\mu$ do CP2, obtém-se os seus novos valores médios respectivamente iguais a $1.910,58 \mathrm{~N} / \mathrm{mm}, 14.856,59$ N.mm e 12,06 com os seus valores de $C_{v}$ inferiores a 15\%, o que demonstra a maior confiabilidade $e$ homogeneidade dos resultados.

\subsection{Discussões dos resultados obtidos com o ensaio dos corpos de prova do modelo 2}

Na série 1 do modelo 2 (Tabela 3), $P_{\text {máx }}$ teve seu valor de $C_{v}$ registrado entre 15 e $30 \%$, o que caracteriza a média dispersão dos resultados. Com os valores de $k_{\mathrm{e}}$, de $\mathrm{A}$ e de $\mu$, tem-se um $\mathrm{C}_{\mathrm{v}}$ acima de $30 \%$ demonstrando a alta dispersão e a heterogeneidade dos resultados. Essa alta dispersão se deve aos valores de $k_{e}$, de $A$ e de $\mu$ alcançados pelos CP's 1, 2 e 3.

O maior valor de $\mathrm{P}_{\text {máx }}$ foi obtido pelo CP1a, o de ke pelo CP1 e os maiores valores de $\mathrm{A}$ e de $\mu$ foram obtidos pelo CP3 (Figura 9). 


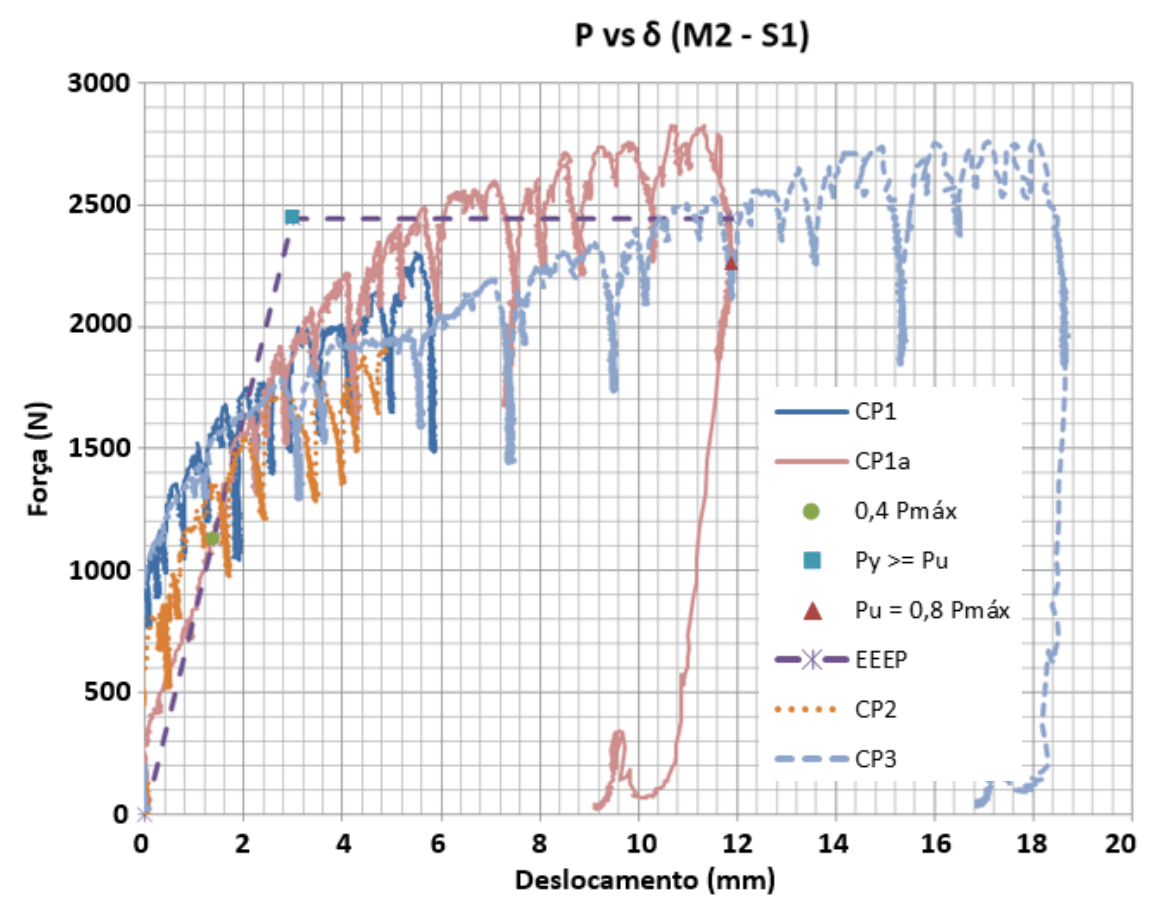

Figura 9 - Gráfico força versus deslocamento dos corpos de prova do modelo 2 (S1).

Na série 2 do modelo 2 (Tabela 3), $P_{\text {máx }}$ teve o seu valor de $C_{v}$ inferior a $15 \%$, o que demonstra a maior confiabilidade e homogeneidade dos resultados. $\mathrm{O} \mathrm{C}_{\mathrm{v}}$ a partir do valor de A foi registrado entre 15 e $30 \%$, o que caracteriza a média dispersão dos resultados. Com os valores de $k_{e}$ e de $\mu$, tem-se um $C_{v}$ acima de $30 \%$ demonstrando a alta dispersão e a heterogeneidade dos resultados. Essa alta dispersão se deve aos altos valores de $k_{\mathrm{e}}$ e de $\mu$ alcançados pelo CP1.

Os maiores valores de $\mathrm{P}_{\text {máx }}$, de $k_{e}$, de $\mathrm{A}$ e de $\mu$ foram obtidos pelo CP1. Esse maior valor de $k_{e}$ se deve ao alto valor de $P_{e}$ e baixo valor de $\delta_{e}$ (Figura 10).

Na série 3 do modelo 2, o $C_{v}$ a partir dos valores de $P_{\text {máx }}$ foi registrado entre 15 e $30 \%$, o que caracteriza a média dispersão dos resultados. Com os valores de $k_{e}$, de $A$ e de $\mu$, tem-se um $C_{v}$ acima de $30 \%$ demonstrando a alta dispersão e a heterogeneidade dos resultados. Essa alta dispersão se deve aos baixos valores de $k_{e}$ e de $\mu$ obtidos no CP2 e ao baixo valor de A alcançado pelo CP3 (Tabela 3).

O maior valor de $\mathrm{P}_{\text {máx }}$ foi obtido no $\mathrm{CP} 2$ e os maiores valores de $k_{e}$, de $\mathrm{A}$ e de $\mu$ foram obtidos pelo CP1. Esse maior valor de $k_{e}$ se deve ao baixo valor de $\delta_{e}$ (Figura 11). 


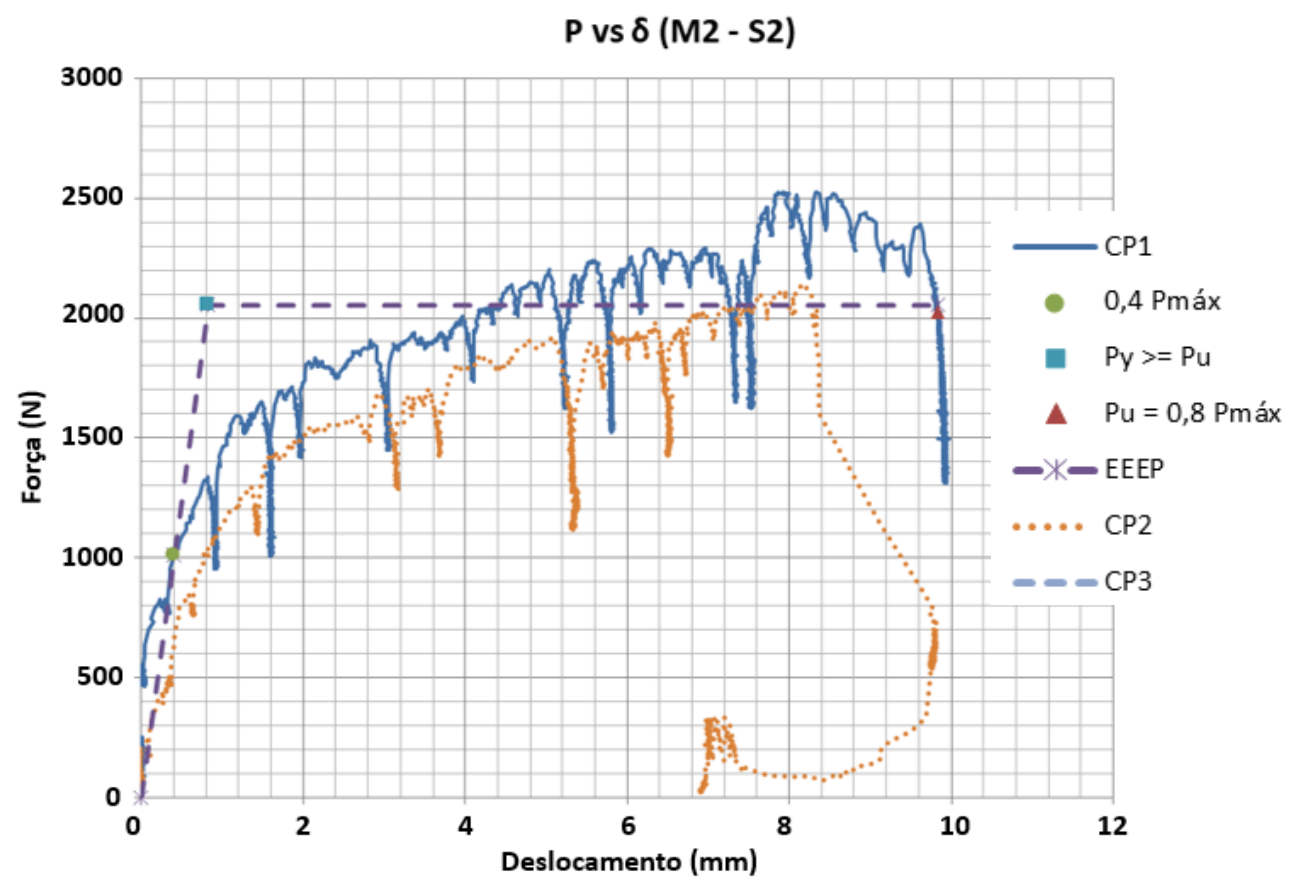

Figura 10 - Gráfico força versus deslocamento dos corpos de prova do modelo 2 (S2).

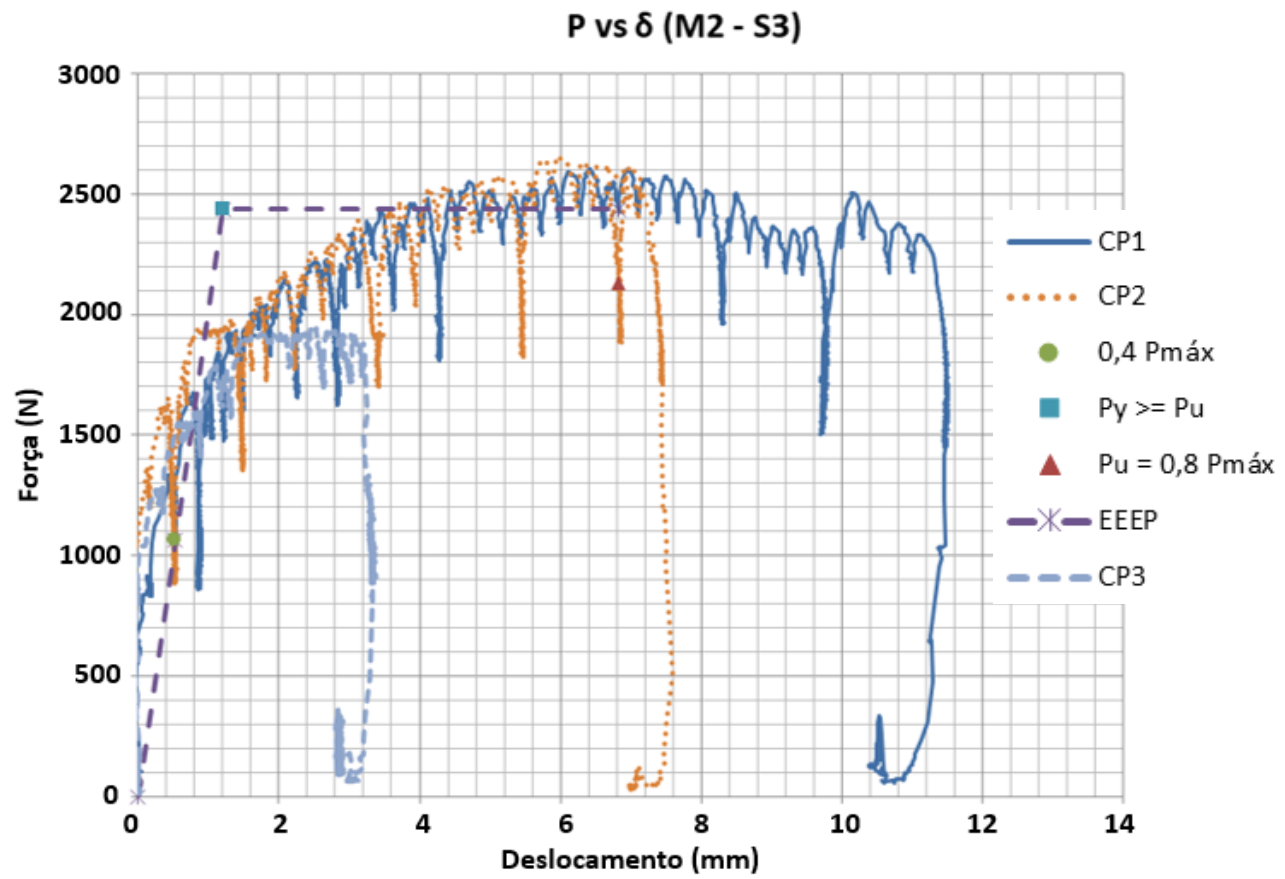

Figura 11 - Gráfico força versus deslocamento dos corpos de prova do modelo 2 (S3).

Desconsiderando os valores de $k_{e}$ e de $\mu$ do CP2 junto com de $P_{\text {máx }}$ e de A do CP3, obtém-se os novos valores médios de $P_{\text {máx }}$ e de $k_{e}$ respectivamente iguais a $2.630,55 \mathrm{~N}$ e $16.719,83 \mathrm{~N} . \mathrm{mm}$ com os seus valores de $C_{v}$ inferiores a $15 \%$, o que demonstra a maior confiabilidade e homogeneidade dos resultados. 
4.4 Influência dos parâmetros de fabricação dos corpos de prova dos modelos 1 e 2 sobre os seus resultados obtidos depois do processamento dos seus dados de ensaio

Tabela 8 - Resultados relativos ao ensaio dos corpos de prova dos Modelos 1 e 2.

\begin{tabular}{|c|c|c|c|c|c|c|c|c|}
\hline Nomenclatura & $P_{\text {máx }}(\mathrm{N})$ & $\mathrm{C}_{\mathrm{v}}(\%)$ & $\begin{array}{c}k_{e} \\
(\mathrm{~N} / \mathrm{mm})\end{array}$ & $\mathrm{C}_{\mathrm{v}}(\%)$ & A (N.mm) & $C_{v}(\%)$ & $\mu$ & $\begin{array}{l}C_{v} \\
\text { (\%) }\end{array}$ \\
\hline M1 S1 & 1.577 & - & 3.133 & - & 8.444 & - & 16 & - \\
\hline M1 S2 & 1.506 & 5 & 15.353 & 1 & 9.424 & - & 76 & - \\
\hline M1 S3 & 1.620 & 8 & 1.554 & 17 & 14.555 & 2 & 11 & 5 \\
\hline M1 S4 & 1.856 & 3 & 1.910 & 6 & 14.856 & 5 & 12 & 7 \\
\hline M2 S1 & 2.450 & 17 & 1.632 & - & 12.697 & - & 4 & - \\
\hline M2 S2 & 2.330 & 12 & 1.312 & - & 16.499 & 24 & 6 & - \\
\hline M2 S3 & 2.630 & 1 & 5.381 & - & 16.720 & 13 & 20 & - \\
\hline
\end{tabular}

\subsubsection{Influência da espessura nominal dos painéis de OSB no Modelo 1}

Com a série 1 (Tabela 8), feita com 9,5 $\mathrm{mm}$ de espessura nominal dos painéis de OSB (tosB), e a série 4 , feita com 11,1 mm de tosB, observou-se que os valores médios de $P_{\text {máx }}$ e de $A$ da série 4 foram respectivamente $17,64 \%$ e 75,95 \% superiores aos valores da série 1 . Porém, os valores de $k_{e}$ e de $\mu$ da série 1 foram respectivamente 63,97 \% e $30,35 \%$ superiores aos valores da série 4 . Observou-se que a variação de tosB teve uma grande influência nos valores de $P_{\text {máx }}$, de $k_{e}$, de $A$ e de $\mu$ da ligação do subsistema de parede. Assim, quanto maior for tosB, maiores serão os valores de $P_{\text {máx }}$ e de $A$ e menores serão os valores de $k_{e}$ e de $\mu$.

\subsubsection{Influência da dimensão nominal da alma do montante no Modelo 1}

Considerando a série 3 (Tabela 8), feita de montantes com dimensão nominal da alma $\left(b_{w}\right)$ igual a $90 \mathrm{~mm}$, e a série 4, com $b_{w}$ igual a $200 \mathrm{~mm}$, observou-se que os valores de $P_{\text {máx, }}$ de $k_{e}$, de $A$ e de $\mu$ da série 4 foram respectivamente $14,56 \%, 22,94 \%, 2,07 \%$ e $10,34 \%$ superiores aos valores da série 3 . Observou-se que a variação de $b_{w}$ não teve uma grande influência nos valores de $P_{\text {máx, }}$ de $k_{e}$, de $A$ e de $\mu$ da ligação do subsistema de parede. Porém, quanto maior for $b_{w}$, levemente maiores serão os valores de $P_{\text {máx, }}$ de $k_{e}$, de $A$ e de $\mu$.

\subsubsection{Influência da espessura nominal dos painéis de OSB no Modelo 2}

Considerando a série 2 (Tabela 8), feita com 11,1 mm de tosB, e a série 3, feita com 9,5 $\mathrm{mm}$ de tosв, observou-se que os valores de $P_{\text {máx }}$, de $k_{e}$, de $A$ e de $\mu$ da série 3 foram respectivamente $12,87 \%, 310,11 \%, 1,34 \%$ e $216,53 \%$ superiores aos valores da série 2. Observou-se que a variação de tosB teve uma pequena influência nos valores de $P_{\text {máx }}$ 
e de A e uma influência muito relevante nos valores de $k_{e}$ e de $\mu$ da ligação do subsistema de parede. Assim, quanto maior for tosB, menores serão os valores de $P_{\text {máx, }}$ de $k_{e}$, de $A$ e de $\mu$.

\subsubsection{Influência da dimensão nominal da alma do montante no Modelo 2}

Considerando a série 1 (Tabela 8), feita de montantes com $b_{w}$ igual a $200 \mathrm{~mm}$, com a série 2 , com $b_{w}$ igual a $90 \mathrm{~mm}$, observou-se que os valores de $P_{\text {máx }}$ e de $k_{e}$ da série 1 foram respectivamente $5,14 \%$ e $24,42 \%$ superiores aos valores da série 2 . Porém, os valores de A e de $\mu$ da série 2 foram respectivamente $29,94 \%$ e $56,93 \%$ superiores aos valores da série 1 . Observou-se que a variação de $b_{w}$ teve uma pequena influência no valore de $P_{\text {máx }}$ e uma influência relevante nos valores de $k_{e}$, de $A$ e de $\mu$ da ligação do subsistema de parede. Assim, quanto maior for $b_{w}$, maiores serão os valores de $P_{\text {máx }} e$ de $k_{\mathrm{e}}$ e menores serão os valores de $\mathrm{A}$ e de $\mu$.

\subsubsection{Influência dos parâmetros sobre os modelos 1 e 2}

Na Tabela 8, com a série 1 do modelo 1 e a série 1 do modelo 2, observou-se que os valores de $P_{\text {máx }}$ e de $A$ da série 1 do modelo 2 foram respectivamente 55,33 \% e 50,37 $\%$ superiores aos valores da série 1 do modelo 1 . Porém, os valores de $k_{e}$ e de $\mu$ da série 1 do modelo 1 foram respectivamente 91,89\% e 295,97 \% superiores aos valores da série 1 do modelo 2 . Observou-se que quanto menores forem tosв e a quantidade de parafusos $\left(Q_{p}\right)$ e maior for a quantidade de montantes $\left(Q_{m}\right)$, menores serão os valores de $P_{\text {máx }}$ e de $A$ e maiores serão os valores de $k_{e}$ e de $\mu$.

Com a série 3 do modelo 1 e a série 3 do modelo 2, observou-se que os valores de $P_{\text {máx, de }} k_{e}$, de $A$ e de $\mu$ da série 3 do modelo 2 foram respectivamente 62,39 \%, 246,26 $\%, 14,87 \%$ e $80,42 \%$ superiores aos valores da série 3 do modelo 1 . Observou-se que quanto maiores forem $t_{o s B}, Q_{p}$ e $Q_{m}$, menores serão os valores de $P_{\text {máx }}$, de $k_{e}$, de $A$ e de $\mu$.

Considerando a série 2 do modelo 2 , observou-se que os valores de $P_{\text {máx }}$ e de $A$ da série 2 do modelo 2 foram respectivamente $43,87 \%$ e 13,36 \% superiores aos valores da série 3 do modelo 1 . Porém, os valores de $k_{e}$ e de $\mu$ da série 3 do modelo 1 foram respectivamente 18,44 \% e 75,44\% superiores aos valores da série 2 do modelo 2 . 
Observou-se que quanto maiores forem $t_{O S B}, Q_{p}$ e $Q_{m}$, menores serão os valores de $P_{\text {máx }}$ e de $A$ e maiores serão os valores de $k_{e}$ e de $\mu$.

Considerando a série 4 do modelo 1 e a série 1 do modelo 2, observou-se que o valor de $P_{\text {máx }}$ da série 1 do modelo 2 foi 32,04 \% superior ao valor da série 4 do modelo 1 . Porém, os valores de $k_{e}$, de $A$ e de $\mu$ da série 4 do modelo 1 foram respectivamente $17,03 \%, 17,00 \%$ e $203,78 \%$ superiores aos valores da série 1 do modelo 2 . Observouse que quanto maiores forem $Q_{p}$ e $Q_{m}$, menor será o valor de $P_{\text {máx }}$ e maiores serão os valores de $k_{e}$, de $A$ e de $\mu$.

\subsection{Comparação entre os resultados da presente pesquisa e os resultados das bibliografias citadas}

O menor valor médio de $P_{\text {máx }}$ e os maiores valores médios de $k_{e}$ e de $\mu$ foram obtidos com a série 2 do modelo 1 . $O C_{v}$ de $P_{\text {máx }}$ e de $k_{e}$ foi respectivamente igual a 4,66 \% e 1,32 \% (Tabela 8). O menor valor médio de $k_{e}$ foi obtido a série 2 do modelo 2. 0 menor valor médio de $\mu$ foi obtido com a série 1 do modelo 2 . Os maiores valores médios de $P_{\text {máx }}$ e de $A$ foram obtidos com a série 3 do modelo 2. O $C_{v}$ de $P_{\text {máx }}$ e de $A$ foi respectivamente igual a 1,58 \% e 12,95 \% (Tabela 8 ). O menor valor médio de A foi obtido com a série 1 do modelo 1 .

$\mathrm{Na}$ Erro! Fonte de referência não encontrada., pode-se observar que os maiores valores de $\mathrm{P}$ e de A foram obtidos por Okasha (2004). Esses valores foram respectivamente superiores de $33,84 \%$ e de $90,79 \%$ aos valores obtidos na presente pesquisa. Os maiores valores de $k_{e}$ e de $\mu$ foram obtidos pela presente pesquisa. Esses valores foram respectivamente superiores de $207,00 \%$ e $230,83 \%$ aos valores obtidos por Okasha (2004). 
Tabela 9 - Comparação entre os resultados (valores máximos ou valores médios*).

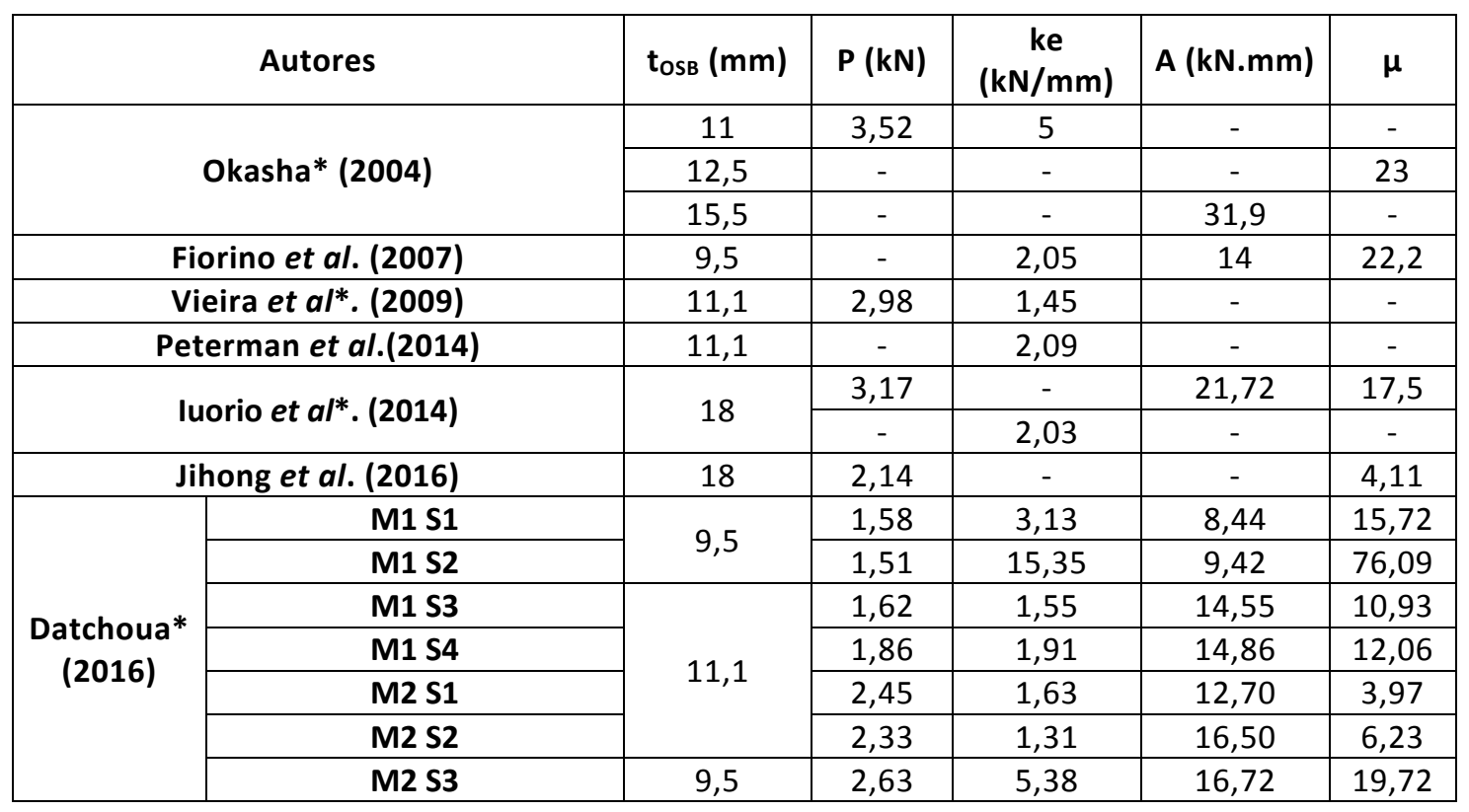

\section{Conclusões}

Como considerações finais, observou-se que:

- Quanto à força máxima obtida na ligação, o valor médio dos CP's feitos com um montante e 10 parafusos (modelo 2-S3) foi quase igual a 2 vezes o valor dos CP's feitos com 2 montantes e 8 parafusos (modelo 1-S2);

- Quanto à rigidez, o valor médio dos CP's feitos com 2 montantes, 9,5 mm de espessura nominal dos painéis de OSB e 8 parafusos (modelo 1-S2) foi quase igual a 12 vezes o valor dos CP's feitos com um montante, $9,5 \mathrm{~mm}$ de espessura nominal dos painéis de OSB e 10 parafusos (modelo 2-S2);

- Quanto à energia dissipada, o valor médio dos CP's feitos com um montante, $90 \mathrm{~mm}$ de dimensão nominal da alma de perfil e 10 parafusos (modelo 2-S3) foi quase igual a 2 vezes o valor dos CP's feitos com 2 montantes, $200 \mathrm{~mm}$ de dimensão nominal da alma de perfil e 8 parafusos (modelo 1-S1);

- E quanto à ductilidade, o valor médio dos CP's feitos com dois montantes, 9,5 mm de espessura nominal dos painéis de OSB, $90 \mathrm{~mm}$ de dimensão nominal da alma de perfil e 8 parafusos (modelo 1-S2) foi quase igual a 19 vezes o valor dos CP's feitos um 
montante, 11,1 mm de espessura nominal dos painéis de OSB, $200 \mathrm{~mm}$ de dimensão nominal da alma de perfil e 10 parafusos (modelo 2-S1).

Para pesquisas futuras na mesma área de atuação, sugere-se executar ensaios de força-deslizamento variando a espessura nominal dos perfis de aço e fabricar a parte do montante desprovida de painéis em perfil tipo caixa para que a ruptura dos corpos de prova ocorra nas ligações, por Pull-over ou por Pull-out, ao invés da ruptura por plastificação do topo dos montantes.

\section{Agradecimentos}

À CAPES, à FAPEMIG e à CNPq pelo apoio financeiro em forma de fomento à pesquisa; à Flasan pelo fornecimento do material e pela fabricação dos modelos; à Construseco pela assistência técnica e a todos os outros colaboradores pelo auxílio durante os ensaios e o tratamento de dados.

\section{Referências bibliográficas}

DATCHOUA, Joseph Stéphane. Estudo Teórico-Experimental do Comportamento da Ligação de Painels de OSB com Perfis do Reticulado Metálico do Sistema Construtivo Light Steel Framing sob Força Monotônica de Cisalhamento. Disponível em: <http://stephane-jayz.blogspot.com.br/2018/03/estudo-teorico-experimental-do.html>. Acesso em: 02 abr. 2018.

FIORINO, L.; DELLA CORTE, G.; LANDOLFO, R., Experimental tests on typical screw connections for cold-formed steel housing. Engineering Structures, v. 29, n. 8, p. 1761-1773, 2007.

IUORIO, O.; FIORINO, L.; LANDOLFO, R.; Testing CFS structures: The new school BFS in Naples. Thin-walled structures, v. 84, p. 275-288, 2014.

OKASHA, A. F., Performance of steel frame/wood sheathing screw connections subjected to monotonic and cyclic loading. Dissertação de Mestrado. Department of Civil Engineering and Applied Mechanics. McGill University, Canadá, 2004. 104p.

POSSAS, Laís de Castro. Análise Experimental sobre a Força Resistente e o Comportamento da Ligação entre o Perfil de Aço e as Painels de OSB com Parafuso Auto-Atarraxante no Sistema Light Steel Framing. Escola de Engenharia, Universidade Federal de Minas Gerais, Belo Horizonte, p. 73, 2015.

PETERMAN, K. D.; NAKATA, N.; SCHAFER, B. W., Hysteretic characterization of cold-formed steel stud-to-sheathing connections. Journal of Constructional Steel Research, v. 101, p. 254264, 2014.

RODRIGUES, Francisco Carlos; CALDAS, Rodrigo Barreto. Steel Framing: Engenharia. Instituto Brasileiro de Siderurgia, Rio de Janeiro, 2a edição revisada, p 224, 2016. 
SANTIAGO, Alexandre Kokke; FREITAS, Arlene Maria Sarmanho; DE CRASTO, Renata Cristina Moraes. Steel Framing: Arquitetura. Instituto Brasileiro de Siderurgia, Rio de Janeiro, 2a edição, p 151, 2012.

VAGH, Shabbir; DOLAN, J. D.; EASTERLING, W. S. Effect of anchorage and sheathing configuration on the cyclic response of long steel-frame shear walls. 2007. (AISI Research Report RP00-6 - Revision 2007).

VIEIRA, L. C. M.; SCHAFER, B. W., Experimental results for translational stiffness of studsheathing assemblies. AISI-COFS supplemental report, 2009.

YE, Jihong; WANG, Xingxing; ZHAO, Mengyuan, Experimental study on shear behavior of screw connections in CFS sheathing. Journal of Constructional Steel Research, v. 121, p. 1-12, 2016. 